\title{
Los bombardeos italianos sobre el País Valenciano durante la Guerra Civil española: un estudio fotográfico
}

\author{
The Italian Bombings over Valencia during the Spanish \\ Civil War: A Photographic Study
}

\author{
Gaspar Díez Pomares \\ Cañada Blanch Centre - LSE, Inglaterra \\ gaspar.pomares@ua.es
}

Recibido: 3-IV-2016

Aceptado: 4-VII-2016

\section{Resumen:}

Durante la Guerra Civil española, el País Valenciano fue una de las zonas más castigadas por los ataques aéreos llevados a cabo por el ejército rebelde en colaboración con sus aliados internacionales, Italia y Alemania. Especialmente destacadas fueron las incursiones perpetradas por la Regia Aeronautica, el ejército aéreo italiano. Desde un punto de vista documental, la importancia de estos ataques por parte de los italianos se encuentra en la disponibilidad de una serie de fotografías tomadas desde los aviones en el momento de las incursiones. Gracias a estas fotografías podemos profundizar en el conocimiento de los bombardeos a través de su contribución a aspectos y datos no incluidos en la documentación escrita. Esta documentación fotográfica hace que sea posible investigar ciertas características de las incursiones como la secuencia del ataque o los proyectiles lanzados, lo que permite una evaluación e interpretación de las razones de estos bombardeos.

Palabras clave: Guerra Civil española, País Valenciano, Bombardeo, Fotografía aérea, Aviación italiana.

\section{Abstract:}

During the Spanish Civil War, Valencia was one of the hardest hit areas by the air raids of the rebel army supported by their international allies, Italy and Germany. The attacks carried out by the Regia Aeronautica -the Italian military air faction, were outstanding. 
From a documentary perspective, the importance of these attacks by the Italians lies in the production of a series of photographs taken from the airplanes during the raids. These images add to our understanding of the bombings as they contribute aspects and data ignored in the written reports. This photographic documentation makes it possible to investigate certain characteristics of the bombings, such as the attack intervals, or the nature of the dropped projectiles, allowing for the assessment and interpretation of the reasons for those bombings.

Keywords: Spanish Civil War, Valencian Country, Bombing, Aerial Photography, Italian Aviation.

Nota preliminar: aclaración sobre las siglas utilizadas.

- USAM.OMS: Ufficio Storico dell'Aeronautica Militare. Fondo Operazione Militare Spagna (Roma).

\section{Introducción ${ }^{1}$}

Durante el período de entreguerras la industria aeronáutica se perfeccionó y cambió de manera vertiginosa. Las implicaciones bélicas de esta escalada adoptaron un papel relevante, culminando en la cruenta batalla aérea que se libró durante la Segunda Guerra Mundial. ${ }^{2}$ La Guerra Civil española no quedó al margen, escribiendo uno de los prólogos de esta tragedia: toda una serie de monografías, publicadas en los más diversos años, ${ }^{3}$ resaltan el protagonismo de las agresiones aéreas sobre el bando enemigo, destacándose como uno de los episodios a tener en cuenta a la hora de calibrar el desarrollo de la Guerra Civil.

1. El presente artículo se enmarca dentro del proyecto de investigación postdoctoral financiado por la Conselleria d'Educació, Investigació, Cultura i Esport de la Generalitat Valenciana (APOSTD/2015/028), que el autor desarrollada en el Cañada Blanch Centre for Contemporary Spanish Studies (London School of Economics, Londres) y en la Universidad de Alicante.

2. Un excelente estudio sobre el tema: MÜLlER, Rolf-Dieter, La muerte caía del cielo. Historia de los bombardeos durante la Segunda Guerra Mundial, Barcelona, Destino, 2008.

3. Una selección: ALCOFAR NASSAES, José Luis, La aviación legionaria en la Guerra española, Barcelona, Euros, 1975; EmiLiani, Angelo, Giuseppe F. GHERGO y Achille vignA, Spagna 1936-39: l'aviazione legionaria, Milán, Intergest, 1973; EMILIANI, Angelo y Giuseppe F. GHERGO, Ali in Spagna. Immagini e storia della guerra civile, 1936-1939, Milán, Giorgio Apostolo, 1997; HOWson, Gerald, Aircraft of the Spanish Civil War. 1936-1939, Londres, Putnan, 1990; INFIESTA PÉREZ, José Luis, Bombardeos del litoral mediterráneo durante la Guerra Civil, vol. 1, Valladolid, Quirón, 1998, (La máquina y la his- toria, 18); INFIESTA PÉREZ, José Luis y José COLL PUJOL, Bombardeos del litoral mediterráneo durante la Guerra Civil, vol. 2, Valladolid, Quirón, 2000, (La máquina y la historia, 21); LANGDON-DAVIES, John, Air Raid. The Technique of Silent Approach High Explosive Panic, Londres, Routledge, 1938; mattioli, Guido, L'aviazione Legionaria in Spagna, Roma, L'Aviazione, 1940; SALAS LARRAZABAL, Jesús, Guerra Aérea, 1936-1939, 4 vol., Madrid, Servicio Histórico y Cultural del Ejército del Aire, 1998-2003; SOlÉ I SABATÉ, Josep M. y Joan Villarroya I FONT, España en llamas. La Guerra Civil desde el aire, Madrid, Temas de Hoy, 2003. 
En el caso concreto del País Valenciano, los ataques aéreos se dieron a lo largo de todo el conflicto. La madrugada del 5 de noviembre de 1936 tuvo lugar el primer bombardeo sobre tierras valencianas, concretamente en la ciudad de Alicante. ${ }^{4}$ Dos años y cinco meses después, el 28 de marzo de 1939, se descargaron las últimas bombas sobre suelo valenciano en la ciudad de Gandía. ${ }^{5}$ Entre estas dos fechas se han contabilizado un total aproximado de 1.850 víctimas, junto con otro total de 637 días de bombardeos, ${ }^{6}$ a los que habría que aumentar ligeramente el número final de ataques llevados a cabo, puesto que en algunos días tuvo lugar más de una incursión.

Buena parte de los bombardeos sufridos sobre el litoral valenciano fueron perpetrados por la denominada Aviazione Legionaria, un cuerpo expedicionario enviado, para colaborar con el bando sublevado, por la Regia Aeronautica, la entonces fuerza aérea del ejército fascista italiano. Desde una perspectiva documental, la Aviación Legionaria guardó especial celo en la recopilación de toda una serie de datos de cada uno de los ataques que llevaban a cabo, siendo los Diari storici, los diarios de vuelo, su mejor exponente. No obstante, la verdadera peculiaridad de la amplia documentación que generaron se encuentra en toda una serie de fotografías aéreas tomadas desde los mismos aviones que realizaban los ataques y en el momento del lanzamiento de los proyectiles.

Partiendo de estas consideraciones generales, el objetivo del artículo será analizar y exponer las posibilidades que ofrece al historiador estas fotografías aéreas, demostrando como permiten acceder a datos no siempre reflejados en los diarios de vuelo. En un primer momento, teniendo presente la autoría de las instantáneas, se profundizará en la denominada Aviazione Legionaria, y particularmente en la facción con base en Mallorca, para conocer mejor las circunstancias que rodearon tanto a este cuerpo expedicionario como a la misma documentación. En un segundo punto se analizarán las fotografías aéreas, desgranando sus capacidades interpretativas e históricas. Particularmente se abordará el fondo documental Operazione Militare Spagna, depositado en Roma, en el Ufficio Storico dell'Aeronautica Militare.

\section{La participación aérea italiana en la Guerra Civil española}

La colaboración de la Italia fascista de Mussolini a favor del bando sublevado fue inmediata y una de las más significativas, ${ }^{7}$ no solamente por la notable

4. ARACIL, Rafael y Joan villarroya, El País Valencià sota les bombes (1936-1939), Valencia, Universidad de Valencia, 2010, p. 17

5. Ibid., p. 107-108.

6. Ibid., p. 177-183 (en esta suma total también se incluyen los bombardeos navales).

7. ROVIGHI, Alberto y Filippo STEFANI, La partecipazione italiana alla guerra civile spagnola (19361939), 2 vol., Roma, Stato Maggiore dell'Esercito 1992. 
aportación en material bélico o por el numeroso capital humano que formó la fuerza terrestre del Corpo Truppe Volontarie, sino también por la creación y consolidación de la ya citada Aviazione Legionaria.

Para entender el alcance y la importancia de la colaboración italiana en la guerra librada desde el aire, un buen indicador es tener presente las cifras materiales y humanas de su participación. La Italia fascista de Mussolini envió, durante toda la guerra, un total de 764 aviones, entre los que conviene destacar 84 bombarderos Savoia S.81, 376 cazas Fiat CR.32 y 100 bombarderos Savoia $\mathrm{S} .79,{ }^{8}$ estos últimos protagonistas indiscutibles de las incursiones que fueron fotografiadas. En lo que respecta tanto al capital humano, como a las acciones llevadas a cabo, la Regia Aeronautica destinó 5.699 hombres a la Guerra Civil española, ${ }^{9}$ sumando un total de 134.899 horas de vuelo, participando en 4.782 acciones de bombardeos y lanzando 11.199.636 kilogramos de explosivos. Igualmente entablaron 259 combates en el aire, derribaron 903 aviones del bando contrario y cerraron el conflicto con un saldo humano fijado en 174 pérdidas. ${ }^{10}$

Teniendo en cuenta las cifras anteriores, no resultó extraño que el bando franquista terminará logrando una evidente superioridad en la guerra librada desde el aire. Con esta superioridad material y humana, la estrategia militar aérea de los sublevados fue clara: llevar a cabo un acoso sistemático sobre la zona leal con la clara intención de ahogar económicamente al bando republicano, destrozando cualquier infraestructura, tanto bélica como industrial (puertos, aeródromos, fábricas, puentes, etc.), pero también atemorizando y manteniendo en constante tensión a la población. ${ }^{11}$ En el caso concreto de los bombardeos sufridos en el País Valenciano, sobre todo desde 1938 y hasta el final de la Guerra Civil, ${ }^{12}$ fue la Aviazione Legionaria delle Baleari, el conjunto de unidades con base en Mallorca, la autora destacada, persiguiendo, igualmente, neutralizar cualquier infraestructura militar, civil o industrial, y minar la moral de las valencianas y los valencianos del momento.

La Italia fascista de Mussolini, además del dominio de un punto estratégico del Mediterráneo en el devenir de la Guerra Civil española, vio en Mallorca una ocasión única para hacerse con el control de un enclave primordial en su

8. PEDRIAli, Ferdinando, Guerra di Spagna e aviazione italiana, 2a ed., Roma, Aeronautica Militare Italiana. Ufficio Storico, 1992, p. 390.

9. COVERDALE, John F, La intervención fascista en la Guerra Civil española, Madrid, Alianza, 1979 , p. 350.

10. PEDRIALI, Ferdinando, Guerra di Spagna..., p. 397.

11. SOlÉ I SABATÉ, Josep M. y Joan VILlARRoyA I Font, España en llamas. La Guerra Civil desde..., p. 19.

12. ARACIL, Rafael y Joan VILlarroya, El País Valencià sota..., pp. 185-195. 
política expansionista: en caso de un cada vez más inminente conflicto europeo, desde este punto se podría controlar las rutas marítimas con el norte de África, aspecto que perjudicaría notablemente a Francia. ${ }^{13}$ De esta manera, la participación italiana en Mallorca arrancó prácticamente desde los inicios de la Guerra Civil. A finales de agosto de 1936, en respuesta al desembarco republicano en Porto Cristo dirigido por el capitán Alberto Bayo, ${ }^{14}$ Mussolini decidió enviar a uno de los miembros más antiguos de sus escuadras fascistas, el extravagante Arconovaldo Bonnacorsi, también conocido como el "Conte Rossi”. Cuando finalmente las tropas al mando del Capitán Bayo terminaron por retirarse, Mallorca quedó situada bajo una cada vez mayor influencia italiana que buscó, por un lado, implantar un orden político que garantizara el ideario fascista de la Falange, por otro lado, imponer una dura represión que asegurara la anulación de los elementos inconformistas. ${ }^{15}$

Paralelamente, la fuerza aérea italiana fue ganando igualmente protagonismo en Mallorca. El primer envío importante de material tuvo lugar a finales de agosto de 1936, con la llegada de dos cazas Fiat CR.32, tres bombardeos Savoia S.81, junto con cañones antiaéreos, munición, bombas y combustible. ${ }^{16}$ Desde esa fecha, la Regia Aeronautica fue progresivamente ganando importancia, hasta la consolidación, el 1938, de una fuerza aérea considerable. En estos momento ya se podía hablar con propiedad de la Aviazione Legionaria delle Baleari formada por el XXV Gruppo Bombardamento Notturno "Pipistrelli delle Baleari", compuesto por las escuadrillas $251^{a}$ y $252^{a}$, que usaban bombardeos Savoia S.81; el X Gruppo Autonomo Caccia "Baleari", integrado por las escuadrillas $101^{a}$ y $102^{a}$, con aviones Fiat CR.32; el $8^{\circ}$ Stormo de Bombardamento Veloce, constituido por el XXVII Gruppo "Falchi delle Baleari" y el XXVIII Gruppo "Falchi delle Baleari", con las escuadrillas $18^{\mathrm{a}}-52^{\mathrm{a}}$ y $10^{\mathrm{a}}-19^{\mathrm{a}}$ respectivamente, todas ellas con bombardeos Savoia S.79; y una sección de hidroaviones. ${ }^{17}$

En relación con los aviones utilizados, particularmente destacaron los bombarderos Savoia-Marchetti S.79, "Sparviere", los aparatos empleados en los bombardeos diurnos y, por lo tanto, desde donde se tomaron las fotografías aéreas de las incursiones. Diseñados inicialmente, en 1934, como aviones de pasajeros

13. COVERDALE, John F., La intervención fascista..., p. 127-128.

14. MASSOT I MUNTANER, Josep, El Desembarcament de Bayo a Mallorca: agost-setembre de 1936, Barcelona, Publicacions de l'Abadia de Montserrat, 1987.

15. BERNANOS, Georges, Los grandes cementerios bajo la luna, Barcelona, Lumen, 2009.

16. COVERDALE, John F., La intervención fascista..., p. 134.

17. USAM.OMS, Serie 5, Carpeta 53, "Aviazione Legionaria delle Baleari. Diario Storico dal 15 Gennaio al 14 Settembre 1938"; y EMILIANI, Angelo, Giuseppe F. GHERGO y Achille VIGNA, Spagna 1936-39..., p. 7. 
por el ingeniero Alessandro Marchetti, no tardaron en convertirse en potentes bombarderos. Los Savoia 79, adaptados al campo de batalla, estaban equipados con tres motores Alfa Romeo 126 C.35 de 750 CV, llegando a lograr una velocidad máxima de $430 \mathrm{~km} / \mathrm{h}$ a 4.000 metros de altura o una velocidad de crucero de $375 \mathrm{~km} / \mathrm{h}$ a 5.000 metros, alcanzando, en todo caso, una cuota máxima entre los 6.500 y los 7.000 metros y una autonomía de 1.900 kilómetros con una carga de 1.250 kilogramos de bombas, el peso máximo de proyectiles que podían almacenar. En cuanto a su sistema defensivo, contaban con tres ametralladoras Breda Safat de $12,7 \mathrm{~mm}$ y otra Breda de $7,7 \mathrm{~mm} .{ }^{18}$

Con estas características, los Savoia 79 podían llevar a cabo sus acciones sobre la costa republicana sin excesivos contratiempos. Por ejemplo, gracias a la velocidad que conseguían y a sus potentes ametralladoras, no necesitaban la protección de cazas, y si eran sorprendidos por la aviación republicana, adoptaban una formación de vuelo cerrada. Además, la situación de su base en Mallorca, unido a su rapidez, a su autonomía y a la altura que conseguían, potenciaban la sorpresa de sus acciones. No resultó extraño que fueran los aviones más utilizados en los bombardeos llevados a cabo sobre el litoral valenciano.

\section{Las fotografías aéreas del fondo Operazione Militare Spagna}

El cuerpo documental más característico, en relación con las fotografías aéreas de los bombardeos sobre suelo valenciano, se encuentra depositado en el fondo Operazione Militare Spagna, ${ }^{19}$ custodiado, a su vez, en el Ufficio Storico dell'Aeronatica Militare, en Roma. ${ }^{20}$ La gran parte de estas instantáneas, recordando lo expuesto en el punto anterior, fueron realizadas por la Aviación Legionaria de las Baleares, concretamente por el $8^{\circ}$ Stormo de Bombardamento Veloce, es decir, por los grupos 27 y 28. En los últimos meses de guerra, determinadas incursiones también fueron fotografiadas por la Aviación Legionaria continental, tanto por el $111^{\circ}$ Stormo de Bombardamento Veloce, con base en Valenzuela (Zaragoza), como por el XXXV Gruppo Autonomo B.V., con su centro de operaciones en Puig

18. Howson, Gerald, Aircraft of the Spanish..., p. 270-273; y PEDRIALI, Ferdinando, Guerra di Spagna..., p. 391.

19. En el Archivo Histórico Municipal de Valencia se puede consultar también un conjunto de este tipo de fotografías, donadas en su momento por el investigador Angelo Emiliani.

20. El fondo no solamente es el más relevante en lo concerniente a estas instantáneas aéreas, igualmente alberga toda clase de documentación vinculada con la actividad que llevó a cabo la Regia Aeronautica en la Guerra Civil española, siendo el archivo de referencia a la hora de investigar este episodio. 
Moreno (Teruel). ${ }^{21}$ Cronológicamente, el porcentaje más elevado de las imágenes disponibles fueron realizadas a partir del año 1938, siendo menores los casos de las incursiones fotografiadas con anterioridad, localizándose fundamentalmente en los meses finales del año 1937.

Comentando más detalladamente las fotografías aéreas de los diferentes bombardeos sobre suelo valenciano, la principal característica de esta documentación, ${ }^{22}$ como ya se ha citado, se encuentra en el hecho de que fueron realizadas desde los mismos aviones que llevaron a cabo las incursiones y en el preciso momento del lanzamiento de los proyectiles. En términos generales, por cada uno de los ataques fotografiados se encuentra un conjunto de imágenes de número variable que oscila entre las dos y las catorce instantáneas en positivo y en blanco y negro. ${ }^{23}$ En todas siempre se observa una vista aérea y en perpendicular del objetivo, sobre una cuota media aproximada en torno a los 5.000 metros de altura.

Otra de sus singularidades es la relación que guardan entre ellas, siguiendo un orden concreto que permite visualizar la secuenciación de la incursión. De esta forma, siempre desde una valoración general, en las primeras fotografías se observa la aproximación al objetivo. En las siguientes se sucede el lanzamiento de las bombas y el impacto de los proyectiles. El conjunto se cierra con unas instantáneas en dónde se muestra el repliegue de los aparatos, pero siempre poniendo en relevancia las citadas consecuencias de los impactos, puesto que en todo momento las imágenes fijan su foco sobre el objetivo. ${ }^{24}$ Un ejemplo ilustrativo de este tipo de fotografías se puede observar en las figuras 1 y 2, correspondientes al bombardeo sobre la ciudad de Valencia el 31 de octubre de 1938.

Por otro lado, también destaca el reverso de las fotografías, acompañadas por una especie de plantilla que muestra toda una serie de referencias del bombardeo, como es el caso de la fecha, la hora, las condiciones climáticas, la cuota absoluta y relativa, el nombre de los mandos, el avión utilizado, e incluso el tipo de cámara y los aspectos técnicos de la toma, ${ }^{25}$ aunque desgraciadamente no

21. Sobre la organización de esta facción: EMILIAnI, Angelo, Giuseppe F. GHERGO y Achille VIGna, Spagna 1936-39..., p. 6.

22. Las siguientes características son igualmente trasladables al resto de fotografías depositadas en el USAM, más allá del ejemplo concreto del País Valenciano, como sería el caso de los bombardeos sobre Cataluña.

23. Existen también un reducido número de fotografías en placas de cristal; todas están reveladas a positivo (USAM.OMS, Serie 2, Carpeta 36, "Bombardamenti effettuati dall'Aviazione legionaria Baleari").

24. Rara vez se fotografían los aviones en vuelo debido a que las tomas de las instantáneas se realizaban sobre la perpendicular del objetivo.

25. Sin más especificaciones al respecto, la cámara fotográfica utilizada respondía a las siglas A.P.R.3. 

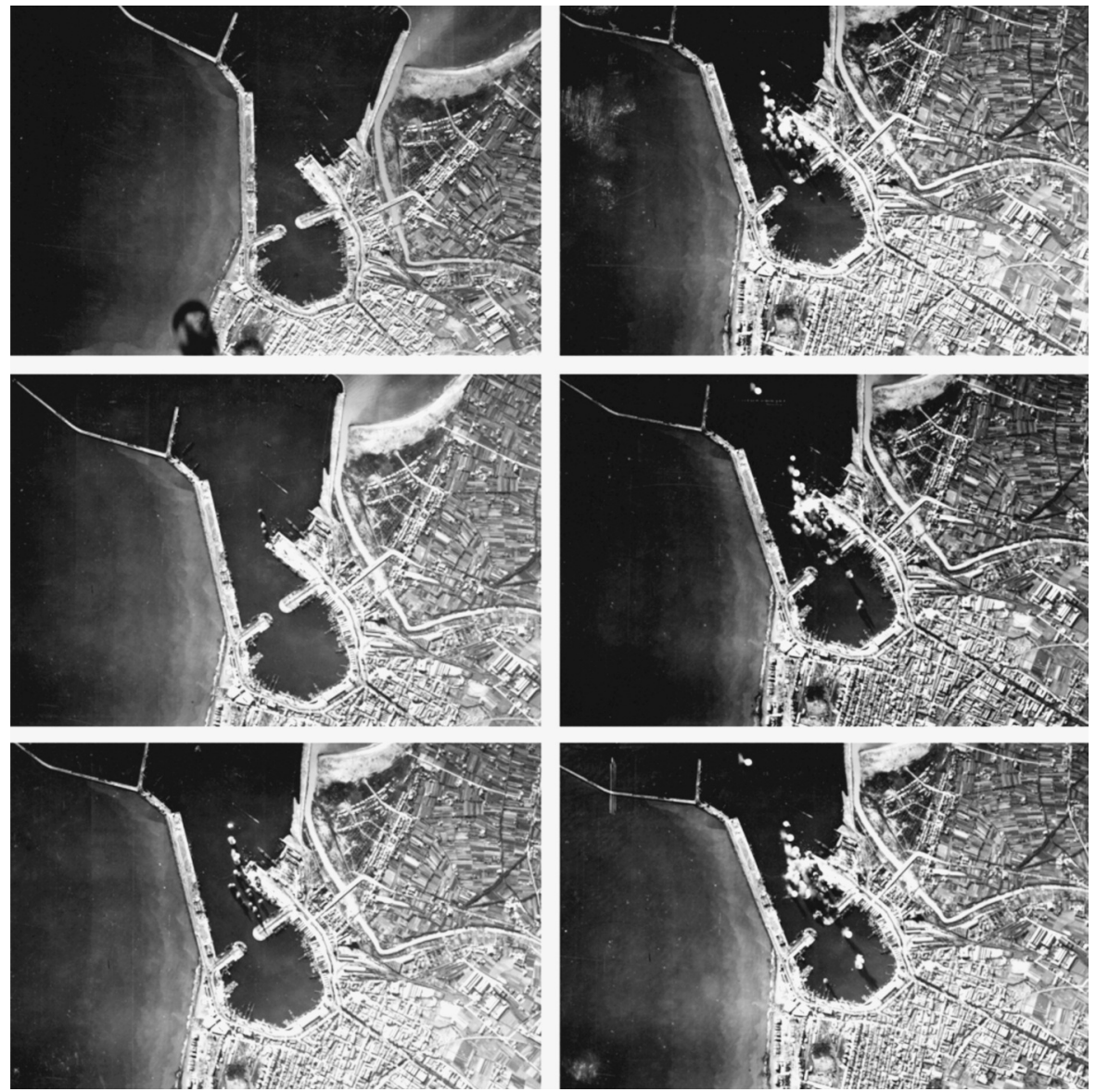

Figura 1. Primeras seis fotografías de la serie de doce que muestran la secuencia del bombardeo que la Aviazione Legionaria delle Baleari llevó a cabo sobre la ciudad de Valencia el 31 de octubre de 1938 (USAM.OMS, Serie 2, Carpeta 21, "Valencia")

se recogían todos los datos, siendo la hora, la cuota, las condiciones climáticas o el personal al mando los más frecuentemente señalados. Comúnmente, esta plantilla suele encontrarse en la primera fotografía de toda la serie.

Estas instantáneas fueron clasificadas en diversos archivadores o carpetas atendiendo a aspectos geográficos o cronológicos. Por ejemplo, una de las clasificaciones más características era la diferenciación por ciudades, de tal manera que en una carpeta se pueden encontrar todos los bombardeos fotografiados sobre un municipio en concreto, o bien, si el número final de instantáneas resultaba muy numeroso para una única carpeta, como por ejemplo es el caso 

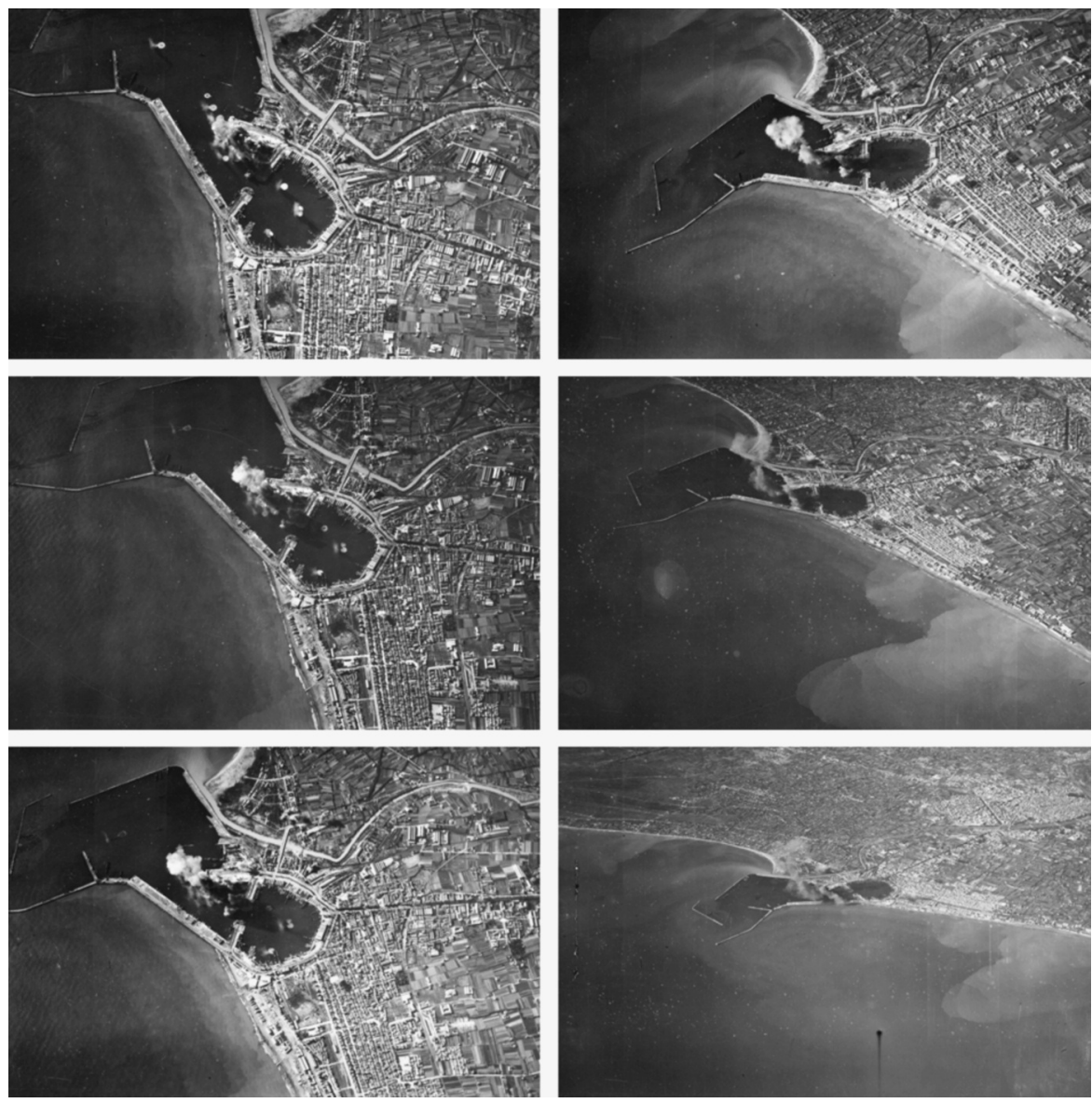

Figura 2. Seis últimas fotografías de la serie de doce que muestran la secuencia del bombardeo que la Aviazione Legionaria delle Baleari llevó a cabo sobre la ciudad de Valencia el 31 de octubre de 1938 (USAM.OMS, Serie 2, Carpeta 21, "Valencia").

de la ciudad de Valencia, se hicieron diferentes archivadores de una misma ciudad, siempre siguiendo la cronología de los ataques. Otras etiquetas que podían ser utilizadas correspondían con una provincia en particular o bien seguían un orden cronológico sin incidir en el factor geográfico. Ello supone que un mismo ataque fotografiado puede encontrarse en diferentes carpetas.

Cada uno de los bombardeos se ordenaron en su correspondiente carpeta en una única hoja, es decir, cada hoja de la carpeta corresponde a una única incursión sobre un municipio un día concreto. Las diferentes fotografías de un ataque en particular quedaban fijadas a la hoja correspondiente por el borde 
superior, manteniendo el orden de la secuencia del ataque, lo que permite observar el desarrollo de la incursión. Por otro lado, en cada una de estas hojas se escribía, a mano o a máquina, o de las dos formas, toda una serie de datos concretos, como la fecha, la cuota conseguida, el objetivo y el grupo encargado de la incursión, alguno de ellos apuntados en el reverso de las fotografías.

El ejemplo anterior resulta el contenedor documental más característico de las fotografías realizadas por la Aviación Legionaria de las Baleares. Igualmente, también se pueden encontrar en los Diari storici, acompañando los partes de alguno de los ataques ${ }^{26} \mathrm{o}$ en los informes que fijaban objetivos, ${ }^{27}$ lo cual apunta el uso, por parte de los mandos militares italianos, de este tipo de documentación.

Las instantáneas realizadas por la Aviación Legionaria continental en los meses finales de la guerra mantiene las principales características descritas anteriormente, no obstante, presentan algunas pequeñas variaciones que conviene tener en cuenta. El número es más reducido, en torno a un par de fotografías, lo que limita la secuenciación del ataque. Por otro lado, son instantáneas que acompañan a los informes del bombardeo en cuestión, es decir, no se confeccionaron archivadores agrupando las diferentes imágenes según un criterio concreto.

El principal cuerpo documental de este tipo de documentación, por lo tanto, está nutrido por los diferentes archivadores que confeccionó la Aviación Legionaria de las Baleares, junto con las fotografías que la Aviación Legionaria continental adjuntó a los informes de los bombardeos que realizó a finales de la Guerra Civil. ${ }^{28}$ Entre estos dos grupos, el número final de bombardeos fotografiados asciende a un total de 233 días, concretamente 62 para la provincia de Alicante, 33 para la de Castellón y 138 para la de Valencia.

En el caso de la provincia de Alicante, los municipios sobre los que se fotografiaron las incursiones fueron Alcoy (7), ${ }^{29}$ Alicante (40), Denia (5), Jávea (1), San Vicente del Raspeig (5), Torrevieja (2) y la Villajoyosa (2). En

26. USAM.OMS, Serie 5, Carpeta 60, "XXVII Gruppo bombardamento veloce. Diario storico II volume".

27. USAM.OMS, Serie 2, Carpeta 36, "Informazioni e note".

28. Fuera de este grupo se debe considerar un reducido número de instantáneas. Por un lado, un grupo menor de fotografías sueltas, no incluidas ni en los archivadores ni en los informes anteriores, correspondientes a incursiones realizadas a finales de 1937 (USAM.OMS, Serie 2, Carpeta 43, "Località diverse"). Por otro lado, bombardeos sobre poblaciones como Liria, Onda o Segorbe perpetrados por la Aviación Legionaria continental a mediados de 1938 (USAM.OMS, Serie 1, Carpetas 8, 9 y 10).

29. En lo sucesivo se señalará entre paréntesis el número de días fotografiados por cada uno de los municipios citados. 
esta provincia, las instantáneas fueron realizadas, a excepción de un único bombardeo ocurrido en Denia el 2 de marzo de 1939, por la Aviación Legionaria de las Baleares entre 1938 y 1939. En la provincia de Castellón, por otro lado, los municipios con los que se cuentan fotografías de bombardeos son Almazora (1), Benicarló (5), Benicassim (1), Burriana (3), Castellón de la Plana (12), Villarreal (8) y Vinaroz (3). Esta vez cronológicamente las incursiones se sitúan a finales de 1937 y los primeros meses de 1938 y todas fueron fotografiadas por la facción de las Baleares. Por último, en la provincia de Valencia las localidades de las que se tienen instantáneas son Gandía (13), Játiva (1), Manises (2), Manuel (1), Sagunto (34) y Valencia (87). En esta provincia, la gran parte de los bombardeos que fueron fotografiados, al igual que Alicante, tuvieron lugar a partir de 1938. Por otro lado, en relación a la autoría, en las localidades de Sagunto, Manises y Valencia, en 1939, parte de los ataques fueron realizados por la Aviación Legionaria continental, el resto por el ejército aéreo de las Baleares. En el anexo 1 se pueden consultar cuatro cuadros, diferenciado por provincias, en dónde se detallan, por municipios, los días de los bombardeos fotografiados.

Respecto a la utilidad concreta de este tipo de documentación por parte de los mandos italianos, por un lado, estas instantáneas servían para fijar futuros objetivos, como de hecho se muestra en los informes pertinentes. ${ }^{30}$ Por otro lado, otra de las utilidades residía en su carácter documental, es decir, dejar constancia visual de estos bombardeos, del mismo modo que se detallaban otros datos relacionados con el número de bombas lanzadas, la hora de las incursiones o los resultados de los ataques. Dado el carácter particular de este tipo de documentación, permitía constatar a posteriori las consecuencias de los bombardeos y el logro de los objetivos marcados antes de las acciones.

Del uso de los militares italianos hay que plantearse la funcionalidad de esta documentación para el historiador. En esta línea, existe diversa bibliografía sobre el tema que ha profundizado en la aplicación de este tipo concreto de documentación, las fotografías aéreas, en las más variadas disciplinas. En el caso concreto de la historia, sin duda, el uso más extendido se ha focalizado en la arqueología. ${ }^{31}$ Cómo señala la investigadora Almudena Orejas Saco del Valle:

30. USAM.OMS, Serie 2, Carpeta 36, "Informazioni e note".

31. ALVISI, Giovanna, La fotografía aérea nell'indagine archeologica, Roma, La Nuova Italia, Scientifica, 1989; DASSIÉ, Jacques, Manuel d'archéologie aérienne, París, Technip, 1978; Stichelbaut, Birger y otros, Images of Conflict. Military Aerial Photograpgy and Archaeology, Newcastle, Cambridge Scholars, 2009; wILSON, D. R., Air Photo Interpretation for Archaelogists, 4a ed., Londres, Batsford, 2000. 
"La fotografía aérea (...) nos permitirá hacer una evaluación de la densidad y forma de distribución de la población y de la riqueza potencial de la zona, así como de los rasgos de la explotación del territorio que han quedado fosilizados, y nos da la oportunidad (...) de remontar el tiempo a partir del presente, descubriendo las huellas dejadas por la explotación y ocupación del suelo en el pasado". ${ }^{32}$

Esta consideración encuentra su principal razón de ser en la denominada fotointerpretación, que como señala, por otro lado, el profesor Felipe Fernández García, debe considerarse como:

"Un proceso a través del cual se trata de extraer la información contenida en las imágenes aéreas. Consiste, en definitiva, en examinar las fotografías con el fin de identificar objetos, determinar su importancia, observar los componentes del paisaje y evaluarlos con el propósito de obtener información de utilidad para la disciplina que utiliza esta técnica". ${ }^{33}$

Desde esta perspectiva, las fotografías de los bombardeos realizados por la Regia Aeronautica durante la Guerra Civil española permiten la posibilidad de rastrear, a través de una rigurosa fotointerpretación, los lugares de los impactos de los proyectiles sobre el territorio valenciano. Este procedimiento debe tomar como referencia el conjunto de fotografías hechas en cada uno de los bombardeos, de tal manera que, en un primer momento, se proceda a la localización de los principales puntos de referencia de las fotografías tomadas durante las incursiones, para posteriormente comparar estas instantáneas con imágenes actuales del mismo espacio. ${ }^{34}$

Esta funcionalidad permite trazar mapas sobre los lugares que fueron bombardeados, ampliando el estudio y las posibilidades de este suceso en particular. Pero también, dentro de las políticas de la denominada "memoria histórica", posibilita la localización de lugares de historia, de tal manera que estos espacios puedan ofrecer la posibilidad de crear una memoria a partir de un hecho histórico concreto. ${ }^{35}$ Este último aspecto abre, sin duda, todo un

32. OREJAS SACO DEL VALLE, Almudena, Del "marco geográfico" a la arqueología del paisaje. La aportación de la fotografía aérea, Madrid, Consejo Superior de Investigaciones Científicas, 1995, p. 121.

33. FERNÁNDEZ GARCÍA, Felipe, Introducción a la fotointerpretación, Barcelona, Ariel, 2000, p. 98.

34. En el caso del País Valenciano resulta muy útil para esta labor la Fototeca histórica del Instituto Valenciano Cartográfico. A través de esta herramienta online se pueden consultar fotografías aéreas de diferentes municipios valencianos a lo largo del siglo XX: <http://fototeca.icv.gva.es/> [consultado: 11-IV-2016].

35. SANTACREU SOLER, José Miguel, "Els llocs arquitectònics d'història i memòria", en Una presó amb vistes al mar. El drama del port d'Alacant, març de 1939, José Miguel Santacreu (ed.), Valencia, Tres i Quatre, 2008, pp. 689-696. 
amplio abanico con claras repercusiones en los más variados ámbitos: económico por el potencial turístico que supone la localización de rutas sobre los bombardeos; pedagógico por el recurso educativo que ofrece la posibilidad de conocer y profundizar sobre un hecho de enorme relevancia para la Guerra Civil en tierras valencianas; memorístico, en conclusión, porque se defiende la articulación de una memoria colectiva sobre un hecho a partir de la historia, evitando distorsiones ideológicas. Aquello que logran estas fotografías, en último término, es la restitución de un hecho concreto en un lugar donde no existen o quedan escasos vestigios materiales de los bombardeos pero que, sin embargo, por la capacidad visual de las fotografías, permite una inmediata identificación. Desde esta perspectiva, las fotografías aéreas, por lo tanto, se convierten en documentos indispensables para poder profundizar sobre el espacio en el cual tuvieron lugar estas incursiones.

Continuando con la funcionalidad que este tipo de documentación ofrece al historiador, igualmente deben destacarse las posibilidades que las fotografías aéreas abren a la hora de profundizar en el estudio y en el análisis tanto de un bombardeo en concreto como en la investigación de los rasgos comunes de las incursiones italianas sobre el litoral valenciano. Profundizando más detenidamente en esta idea, uno de los aspectos clave es observar el papel que cumplen estas imágenes a la hora de compensar y contrastar los denominados Diari storici, los diarios de vuelo, la que se puede considerar la principal documentación italiana empleada a la hora de profundizar en un ataque concreto. La información que se extrae de esta documentación escrita resulta, en último término, valiosa e imprescindible en el estudio de los ataques aéreos sobre el suelo valenciano. Pero de la misma forma, no debe olvidarse que es una documentación con limitaciones y problemas que las fotografías aéreas ayuda a compensar.

Dos deben ser los aspectos, en este sentido, a tener en cuenta. Por un lado, siguiendo el ejemplo de la Aviación Legionaria de las Baleares, cada una de las unidades en la que estaba estructurada, recordando lo expuesto en el punto anterior, realizaba su propio diario. Esta característica, antes que ser un problema, ayuda a ampliar los datos específicos de un ataque en concreto. No obstante, de la lectura de toda esta serie de diarios queda manifiesto que se redactaban de manera independiente y raramente contrastados entre ellos, no en vano, los mandos italianos, conocedores de este aspecto, mandaron una circular a principios de 1939 con toda una serie de reglas a seguir con la intención de unificar los criterios de redacción y los contenidos a mostrar. ${ }^{36}$ Por otro

36. USAM.OMS, Serie 7, Carpeta 76, "Registri di volo e diari storici. Compilazione e transmissione". 
lado, otro de los aspectos que caracteriza, y a la vez limita el papel que juega esta documentación escrita en la labor del historiador, son los datos reflejados en la misma. En términos generales, los diarios de vuelo resultan particularmente interesantes desde un punto de vista cuantitativo, ofreciendo toda una serie de datos concretos en relación al número de bombas lanzadas, los aviones empleados, el personal al mando, el alcance o no del objetivo inicial o las horas de despegue, aterrizaje e impacto de las bombas. Sin embargo, comúnmente no recogen aspectos de carácter más cualitativo de cara a analizar el procedimiento seguido durante la incursión.

Teniendo presente las características y el momento concreto en que fueron realizadas las fotografías aéreas, un riguroso análisis de esta documentación permite profundizar en determinados detalles de un bombardeo que no siempre han quedado recogidos en los diarios de vuelo. Partiendo de la visualización del impacto de los proyectiles, uno de los datos que ofrecen estas imágenes es la posibilidad de observar el procedimiento empleado en el lanzamiento de los mismos, sobre todo en el punto referido al modo en que se combinaban las bombas de mayor y de menor peso.

Continuando con el análisis de los impactos observables, otro de los aspectos que permiten conocer estas fotografías es el alcance real de una determinada incursión. Precisamente comparando las imágenes tomadas en el momento del ataque con otras más actuales, siguiendo el modelo de análisis citado anteriormente, se puede observar las zonas afectadas en un bombardeo concreto y completar los datos ofrecidos en los diarios de vuelo, en dónde generalmente se señalaba el alcance total o parcial del objetivo inicial y no del resto de zonas afectadas ese día en particular. Igualmente, los impactos observables permiten conocer el número de bombas lanzadas en el conjunto de las fotografías. Este último punto, partiendo del total de proyectiles empleados que se citan en los diarios de vuelo, ayuda a conocer el número de pasadas que se llevó a cabo sobre un objetivo concreto. Por otro lado, recordando la secuencialidad y el orden seguido en el conjunto de fotografías de un ataque determinado, estos dos aspectos ayudan a conocer la ruta utilizada por los aviones, las maniobras que llevaron a cabo, así como la dirección de tiro seguida durante el ataque. Todos estos datos permiten profundizar en el que sin duda es uno de los capítulos más controvertidos y trágicos de los bombardeos sobre el litoral valenciano y mediterráneo en general, como es el alcance de objetivos civiles durante las incursiones, analizable en la visibilidad de los impactos o en la ruta y la dirección seguida por los aviones durante el vuelo.

No obstante, esta documentación visual, al igual que los diarios de vuelo, también presenta una serie de limitaciones que es necesario tener en cuenta. 
Por un lado, el número de fotografías disponibles en un bombardeo en concreto puede quedar reducido a una, dos o tres fotografías como máximo, lo que limita el análisis de aspectos relacionados con la dirección de tiro o la ruta seguida por los aviones. Por otro lado, las fotografías, en términos generales, se realizaban desde un mismo avión y por un mismo fotógrafo. Este aspecto supone un problema en aquellos ataques de los que se tiene constancia, por ejemplo, que se realizara más de una pasada o que actuaran al menos dos escuadrillas por separado, lo que sitúa en estos casos fuera del marco de las fotografías una parte de la incursión. Aún así, estos dos puntos antes que ser vistos como un escollo insalvable en la investigación de un bombardeo en particular, deben ser tenidos en cuenta a la hora evitar caer en el error de analizar una parte por el todo.

\section{Conclusión}

Este artículo ha puesto el foco en el que sin duda fue uno de los episodios más trágicos sufridos en el País Valenciano durante la Guerra Civil española: los bombarderos aéreos realizados por la denominada Aviazione Legionaria, el cuerpo expedicionario que la Regia Aeronautica envió a España para colaborar con el bando sublevado. El fondo documental Operazione Militare Spagna, depositado en el Ufficio Storico dell'Aeronautica Militare, es sin duda el referente a la hora de investigar este episodio desde la perspectiva de los autores de los bombardeos. De entre la innumerable y variada documentación custodiada en este fondo, particularmente se ha incidido en toda una serie de fotografías aéreas tomadas desde los aviones que participaron en las incursiones y en el preciso momento del lanzamiento de los proyectiles. Las características definitorias de estas imágenes, su organización documental, así como los municipios y las fechas de las que se dispone fotografías de los bombardeos han sido los principales aspectos abordados.

Precisamente las peculiares características de estas instantáneas son las que permiten al historiador utilizarlas más allá de un fin meramente ilustrativo. Por un lado, hacen posible rastrear en el presente las huellas de estos ataques, encaminando los resultados hacia la construcción de políticas de memoria con una sólida base histórica. Por otro lado, la secuenciación de las imágenes, el impacto de los proyectiles, junto con otros aspectos recogidos en las fotografías, ayudan a ahondar tanto en un bombardeo en concreto como en los rasgos comunes de las diferentes incursiones italianas. Ello se debe fundamentalmente porque posibilitan trabajar con aspectos como la dirección de tiro, la ruta seguida por los aviones o el alcance de los proyectiles sobre el municipio bombardeado, características que no siempre quedan recogidas, en lo 
tocante a la documentación exclusivamente italiana, en los denominados Diari storici, es decir, los diarios de vuelo.

No obstante, a pesar del interés y el valor de las fotografías aéreas, generalmente su uso más característico ha quedado reducido a una mera ilustración de la documentación escrita. ${ }^{37}$ Igualmente conviene matizar que sería un notable error considerar que estas imágenes tienen mayor importancia que los documentos escritos. Antes bien, tanto las fotografías como los textos deben cumplir por igual la misma función. Ambos son documentos elaborados por una misma fuente, el ejército fascista italiano, con una intencionalidad particular: dejar constancia del procedimiento, de los resultados y de los costes de cada uno de los ataques aéreos que perpetraron. Este vínculo que los unió en su origen es el mismo que debe mantenerse en la investigación histórica posterior. Por esta razón ambos documentos cumplen una doble función: por un lado, ofrecen la posibilidad de ser contrastados entre ellos, dotando de mayor rigor a sus respectivos contenidos; por otro lado, al ser complementarios, abren el abanico de los datos a investigar, permitiendo profundizar más detalladamente en el desarrollo de estos bombardeos, así como las circunstancias que los envolvieron.

37. Una notable excepción: NAVARRo Bonilla Diego y Guillermo viCENTE CANO, "Photographic Air Reconnaissance during the Spanish Civil War, 1936-1939: Doctrine and Operations", War in History, vol. 20, no 3 (2013), pp. 345-380. 


\section{Anexo 1}

Principales bombardeos fotografiados por la Aviazione Legionaria en el País Valenciano durante la Guerra Civil española

Elaboración propia a partir del fondo USAM.OMS

Nota:

- Los días marcados con un asterisco fueron bombardeados por la Aviación Legionaria continental.

- El 22 de enero de 1939 la ciudad de Valencia fue bombardeada, tanto por la Aviación Legionaria de las Baleares como por la continental.

\begin{tabular}{|c|c|c|c|c|c|c|c|}
\hline \multicolumn{8}{|c|}{ ALICANTE } \\
\hline & Alcoy & Alicante & Denia & Jávea & San Vicente & Torrevieja & Villajoyosa \\
\hline \multicolumn{8}{|l|}{1937} \\
\hline \multicolumn{8}{|l|}{ Octubre } \\
\hline \multicolumn{8}{|l|}{ Noviembre } \\
\hline \multicolumn{8}{|l|}{ Diciembre } \\
\hline \multicolumn{8}{|l|}{1938} \\
\hline \multicolumn{8}{|l|}{ Enero } \\
\hline Febrero & & 5 & & & & & \\
\hline \multicolumn{8}{|l|}{ Marzo } \\
\hline \multicolumn{8}{|l|}{ Abril } \\
\hline Mayo & & 17,25 & & & & & \\
\hline Junio & & $6,7,10,13,15,21,25,26,27$ & 18 & & $9,17,28$ & & 8 \\
\hline Julio & & $14,17,20,25,29$ & 22,23 & 23 & 4 & & \\
\hline Agosto & & $6,8,10,13,20,30$ & & & & 25 & 15 \\
\hline Septiembre & $20,22,23$ & $6,18,30$ & & & & 5 & \\
\hline Octubre & 16 & 31 & & & & & \\
\hline \multicolumn{8}{|l|}{ Noviembre } \\
\hline Diciembre & & 7 & & & & & \\
\hline \multicolumn{8}{|l|}{1939} \\
\hline Enero & 29 & 25,26 & 21 & & & & \\
\hline Febrero & 9,11 & $6,10,12,13,18,19,21$ & & & & & \\
\hline Marzo & & $3,6,25$ & $2^{*}$ & & 1 & & \\
\hline Total días: & 7 & 40 & 5 & 1 & 5 & 2 & 2 \\
\hline
\end{tabular}




\begin{tabular}{|c|c|c|c|c|c|c|c|}
\hline \multicolumn{8}{|c|}{ CASTELLÓN } \\
\hline & Almazora & Benicarló & Benicasim & Burriana & Castellón de la Plana & Villareal & Vinaroz \\
\hline \multicolumn{8}{|l|}{1937} \\
\hline Octubre & & 18,20 & & & 15 & & \\
\hline \multicolumn{8}{|l|}{ Noviembre } \\
\hline Diciembre & 12 & & & 13,22 & 21,22 & $5,13,20$ & \\
\hline \multicolumn{8}{|l|}{1938} \\
\hline Enero & & & & 16 & 11,21 & 18 & \\
\hline Febrero & & & & & & $18,21,22$ & \\
\hline Marzo & & 15,20 & 16 & & $15,16,28,30$ & 8 & 19 \\
\hline Abril & & 3 & & & $1,2,3$ & & 7,9 \\
\hline \multicolumn{8}{|l|}{ Mayo } \\
\hline \multicolumn{8}{|l|}{ Junio } \\
\hline \multicolumn{8}{|l|}{ Julio } \\
\hline \multicolumn{8}{|l|}{ Agosto } \\
\hline \multicolumn{8}{|l|}{ Septiembre } \\
\hline \multicolumn{8}{|l|}{ Octubre } \\
\hline \multicolumn{8}{|l|}{ Noviembre } \\
\hline \multicolumn{8}{|l|}{ Diciembre } \\
\hline \multicolumn{8}{|l|}{1939} \\
\hline \multicolumn{8}{|l|}{ Enero } \\
\hline \multicolumn{8}{|l|}{ Febrero } \\
\hline \multicolumn{8}{|l|}{ Marzo } \\
\hline Total días: & 1 & 5 & 1 & 3 & 12 & 8 & 3 \\
\hline
\end{tabular}




\begin{tabular}{|c|c|c|c|c|c|}
\hline \multicolumn{6}{|c|}{ VALENCIA (cuadro I) } \\
\hline & Gandía & Játiva & Manises & Manuel & Sagunto \\
\hline \multicolumn{6}{|l|}{1937} \\
\hline \multicolumn{6}{|l|}{ Octubre } \\
\hline \multicolumn{6}{|l|}{ Noviembre } \\
\hline Diciembre & & & & & $3,12,19,22,24,26$ \\
\hline \multicolumn{6}{|l|}{1938} \\
\hline Enero & & & & & $7,8,13,15,18,19,21,27$ \\
\hline Febrero & & & & & $4,5,8,18,22,25$ \\
\hline Marzo & & & & & $12,16,20,31$ \\
\hline Abril & & & & & 3 \\
\hline \multicolumn{6}{|l|}{ Mayo } \\
\hline Junio & 18,27 & & & & \\
\hline Julio & 22 & & & & \\
\hline Agosto & 16,19 & & & & 23,24 \\
\hline Septiembre & & & & & 21 \\
\hline Octubre & & & & & 17 \\
\hline Noviembre & 20 & & & & 8 \\
\hline Diciembre & & & & & 3 \\
\hline \multicolumn{6}{|l|}{1939} \\
\hline Enero & 21 & & & & \\
\hline Febrero & $12,19,20,28$ & 12 & & 11 & $7^{*}, 8^{*}, 9^{*}$ \\
\hline Marzo & 1,28 & & $6^{*}, 7^{*}$ & & \\
\hline Total días: & 13 & 1 & 2 & 1 & 34 \\
\hline
\end{tabular}




\begin{tabular}{|c|c|}
\hline & VALENCIA (cuadro II) \\
\hline & Valencia \\
\hline 1937 & \\
\hline Octubre & \\
\hline Noviembre & \\
\hline Diciembre & \\
\hline 1938 & \\
\hline Enero & $16,18,19,20,26$ \\
\hline Febrero & \\
\hline Marzo & \\
\hline Abril & 25 \\
\hline Mayo & $5,7,20,23,28,30$ \\
\hline Junio & $4,6,7,14,15,16,17,19,21,22,25,27$ \\
\hline Julio & $10,14,19,20,28,29$ \\
\hline Agosto & $4,5,11,13,30$ \\
\hline Septiembre & $4,9,10$ \\
\hline Octubre & $5,8,15,22,27,29,31$ \\
\hline Noviembre & $3,8,9,12,14,25,28$ \\
\hline Diciembre & $2,14,27,28,30,31$ \\
\hline 1939 & \\
\hline Enero & $3,6,8,12,14,19,20,22,24^{*}, 25^{*}$ \\
\hline Febrero & $2^{*}, 8^{*}, 9^{*}, 10^{*}, 11^{*}, 12^{*}, 15^{*}, 16^{*}, 18^{*}, 27^{*}, 28^{*}$ \\
\hline Marzo & $1^{*}, 5^{*}, 7^{*}, 11^{*}, 14^{*}, 20^{*}, 21,22$ \\
\hline Total días: & 87 \\
\hline Total días pro & vincia de Valencia: 138 (cuadros I y II) \\
\hline Total País Val & enciano: 233 \\
\hline
\end{tabular}




\section{BIBLIOGRAFÍA}

ALCOFAR NASSAES, José Luis, La aviación legionaria en la Guerra española, Barcelona, Euros, 1975.

ALVISI, Giovanna, La fotografía aérea nell'indagine archeologica, Roma, La Nuova Italia, Scientifica, 1989.

ARACIL, Rafael; VILlarroya, Joan, El País Valencià sota les bombes (1936-1939), Valencia, Universidad de Valencia, 2010.

BERNANOS, Georges, Los grandes cementerios bajo la luna, Barcelona, Lumen, 2009.

COVERDALE, John F., La intervención fascista en la Guerra Civil española, Madrid, Alianza, 1979.

DASSIÉ, Jacques, Manuel d'archéologie aérienne, París, Technip, 1978.

EMILIANI, Angelo; GHERGo Giuseppe F; VIGNA, Achille, Spagna 1936-39: l'aviazione legionaria, Milán, Intergest, 1973.

EMILiani, Angelo; GHERGo, Giuseppe F., Ali in Spagna. Immagini e storia della guerra civile, 1936-1939, Milán, Giorgio Apostolo, 1997.

FERNÁNDEZ GARCÍA, Felipe, Introducción a la fotointerpretación, Barcelona, Ariel, 2000. HOWson, Gerald, Aircraft of the Spanish Civil War. 1936-1939, Londres, Putnan, 1990 INFIESTA PÉREZ, José Luis, Bombardeos del litoral mediterráneo durante la Guerra Civil, vol. 1, Valladolid, Quirón, 1998, (La máquina y la his- toria, 18).

INFIESTA PÉREZ, José Luis; COLL PUJOL, José, Bombardeos del litoral mediterráneo durante la Guerra Civil, vol. 2, Valladolid, Quirón, 2000, (La máquina y la historia, 21). LAngdon-davies, John, Air Raid. The Technique of Silent Approach High Explosive Panic, Londres, Routledge, 1938.

MASSOT I MUNTANER, Josep, El Desembarcament de Bayo a Mallorca: agost-setembre de 1936, Barcelona, Publicacions de l'Abadia de Montserrat, 1987. MACROBUTTON HTMLDirect

MATTIOLI, Guido, Laviazione Legionaria in Spagna, Roma, LAviazione, 1940.

MÜLLER, Rolf-Dieter, La muerte caía del cielo. Historia de los bombardeos durante la Segunda Guerra Mundial, Barcelona, Destino, 2008.

NAVARRO Bonilla Diego; VICENTE CANO, Guillermo, "Photographic Air Reconnaissance during the Spanish Civil War, 1936-1939: Doctrine and Operations", War in History, vol. 20, no 3 (2013), pp. 345-380.

OREJAS SACO DEL VAlLE, Almudena, Del "marco geográfico" a la arqueología del paisaje. La aportación de la fotografía aérea, Madrid, Consejo Superior de Investigaciones Científicas, 1995.

PEDRIALI, Ferdinando, Guerra di Spagna e aviazione italiana, 2a ed., Roma, Aeronautica Militare Italiana. Ufficio Storico, 1992.

ROVIGHI, Alberto; STEFANI, Filippo, La partecipazione italiana alla guerra civile spagnola (19361939), 2 vol., Roma, Stato Maggiore dell'Esercito 1992.

Salas larrazabal, Jesús, Guerra Aérea, 1936-1939, 4 vol., Madrid, Servicio Histórico y Cultural del Ejército del Aire, 1998-2003. 
SANTACREU SOlER, José Miguel, "Els llocs arquitectònics d'història i memòria", en Una presó amb vistes al mar. El drama del port d'Alacant, març de 1939, José Miguel Santacreu (ed.), Valencia, Tres i Quatre, 2008, pp. 689-696.

SOlÉ I SABATÉ, Josep M.; VILlaRroya I FONT, Joan, España en llamas. La Guerra Civil desde el aire, Madrid, Temas de Hoy, 2003.

stichelbaut, Birger y otros, Images of Conflict. Military Aerial Photograpgy and Archaeology, Newcastle, Cambridge Scholars, 2009.

WILson, D. R., Air Photo Interpretation for Archaelogists, 4a ed., Londres, Batsford, 2000. 